\title{
Karakterisasi parameter model prediksi untuk eleviasi dari perangkap kemiskinan melalui intervensi kebijakan fiskal
}

\section{Parameters charaterization of prediction model on endeavouring proverty eleviation through fiscal policy}

\author{
Agus Setiawan, S. Bakri, A. Effendi, I. Nurhaida \\ Jurusan Kehutanan Fakultas Pertanian Universitas Lampung. \\ Jurusan Ilmu Administrasi Niaga FISIP Universitas Lampung \\ Jurusan Ilmu Komunikasi FISIP Universitas Lampung \\ Korespondensi: Jalan Sumanteri Brojonegoro Nomor 1 Bandar Lampung 35145 \\ E-mail:aslulia@yahoo.com
}

\begin{abstract}
The purpose of this study was to develop a model of poverty eleviation in the buffer zone of National Park through the optimization of the impact of the fuel subsidiary reallocation (BLT), statrted from April to October 2013 in three villages which representent ethnic culture in Lampung, Java, and the mixture of both, selecting 50 poor households (RTM) who received BLT (direct cash assistance) in 2005. In-depth interview was conducted to capture the economy performance of each household. Qualitative probability model was applied to the response variable $\left(Y_{i}\right)$ that were scored 1 for those have been exited from the poverty and scored 0 if not yet. The predictor variables used $\left(X_{i j}\right)$ including: fuel prices (Rp/liter), total of BLT (Rp), demographics (age, sex, family head education, as well as the number of dependents), the value of productive assets ( $R p$ million/household), revenue from damar resin, and other sources ( $R p$ million/household), access to public services, the distance to the border of BBSNP, the availlability of PNPM (national project of community empowermnent that scored 1 if any and 0 if not), the performance of social capital and the extention program conveyed. The Minitab Version 16 was employed for exzamining the goodness to the model and the significancy of the parameters pursued at the level of 5\% and 10\%. The conclusions were the exit capability against poverty were significantly affected by: fuel prices, the ammount of the BLT, the exisistency of PNPM, gender \& education of household, number of dependents, the distance to central districts, the presence of electricity, the power of social capital, land ownership of both damar agroforest and paddy field acreages, the owner of productive assets such as ruminants. Accordingly, there were no culturetribe significantly affected by the existing from of poverty, which means that the poverty in this region was more structural cause than that of the cultural one.
\end{abstract}

Keywords: damar agroforest, national park, social safety net of oil subsidiary, poverty exite,ethnical-cultural

\begin{abstract}
Abstrak
Tujuan penelitian ini adalah untuk mengembangkan model pengentasan kemiskinan di kawasan penyangga taman nasional melalui optimalisasi dampak pengalihan subsidi BBM (bahan bakar minyak). Penelitian dilakukan bulan April sampai Oktober 2013 di tiga desa miskin representasi dari budaya Etnis Lampung, Jawa, dan campuran masing-masing dipilih 50 rumah tangga miskin (RTM) yang mendapat BLT (bantuan langsung tunai) tahun 2005. Dilakukan wawancara mendalam untuk menangkap kinerja perekonomian tiap KK. Model peluang kualitatif diterapkan dengan variabel respon $\left(Y_{i}\right)$ yang diberi skor 1 untuk rumah yang telah eksit dari kemiskinan dan diberi skor $O$ jika belum. Variabel prediktor yang digunakan $\left(X_{i j}\right)$ meliputi: harga BBM (Rp/liter), total dari BLT (Rp),demografi (umur, kelamin dan pedidikan KK, serta jumlah tanggungan), nilai aset produktif (Rp juta/KK), pendapatan dari getah damar dan pendapatan sumber lain (Rp/bln), akses ke layanan publik,jarak ke perbatasan TNBBS (Taman Nasional Bukit Barisan Selatan), bermukim di desa yang pernah ada PNPM (diberi skor 1 ) ataukah tidak (diberi skor 0 ), kinerja modal sosial dan kinerja penyuluhan.Optimasi parameter digunakan Minitab Version 1. UjiGaldUji Wald pada taraf nyata $5 \%$ dan $10 \%$ berurut untuk menguji kebaikan-suai dari model dan untuk parameter.Simpulan yang diperoleh dari penelitian ini adalah kemampuan eksit dari perangkap kemiskinan dipengaruhi secara nyata oleh: harga BBM, besarnya BLT, adanya PNPM, jenis kelamin KK, jumlah tanggungan, tingkat pendidikan KK, jarak pusat kecamatan, adanya layanan listrik, kekuatan modal sosial, penyuluhan, luasan kepemilikian lahan repong dan sawah serta aset produktif berupa ternak ruminan. Pengaruh budaya tidak berpengaruh nyata berarti kemiskinan di wilayah ini lebih bersifat struktural ketimbang kultural.
\end{abstract}

Kata kunci: repong damar,taman nasional,subsidi BBM, peluang eksit dari kemiskinan, etnis budaya 


\section{Pendahuluan}

Mengapresiasi adanya praktek sistem wanatani yang dapat dikatagorikan sebagai best practice dalam pengelolaan hutan berbasis masyarakat secara turun-temurun sejak tahun 1700-an, para ahli yang tergabung dalam ICRAF (International Centre for Research in Agroforestry yang sekarang berubah naman menjadi World AgroforestryCentre) berhasil memediasi konflik penguasaan hutan antara Masyarakat Adat Lampung Barat dengan Pemerintah Provinsi Lampung maupun Pemerintah Pusat. Mediasi dilaksanakan dengan menetapkan areal budidaya hutan repong damar seluas 29.000 ha di wilayah Lampung sebagai KDTI (Kawasan Dengan Tujuan Istimewa) dengan Surat Keputusan Menteri Kehutanan Nomor 47/KPTs-II/1998 (Foresta 2000) yang sekaligus mengakhiri konflik tersebut. KDTI selain memiliki ciri kebersinambungan dari sisi aspek teknik budidaya, sistem repong damar juga memiliki ciri keberlanjutan dari sisi social-legal aspect, karena KDTI merupakan suatu bentuk pengakuan dari pemerintah (sebagai otoritas pemegang kebijakan publik) yang telah menjamin hak-hak masyarakat adat lokal dalam pemanfaatan wilayah hutan tersebut yang tidak akan dialihkan sebagai konsesi kepada pihak lain.

Ditinjau dari sudut konteks kewilayahan, sistem repong damar memiliki hubungan topologis yang sangat penting mengingat posisinya yang berbatasan langsung dengan kawasan konservasi yang ketat yaitu Taman Nasional Bukit Barisan Selatan (TNBSS). Artinya kawasan KDTI ini sekaligus menjadi kawasan penyangga TNBBS, yang telah menjadi kawasan konservasi sumberdaya hayati yang kian menjadi sorotan dunia internasional tersebut. Nyhus dan Tilson (2004) membuktikan bahwa frekuensi konflik antara manusia versus satwa liar di kawasan penyangga kawasan TNBBS yang berpola wanatani (seperti repong damar) ini jauh lebih rendah dari pada kawasan penyangga yang berpola hutan produksi. Begitu pula di beberapa tempat di kawasan penyangga Taman Nasional Way Kambas (TNWK) yang berpola tanam identik dengan sistem wanatani (multistara atau agroforestry).

Kedua pakar ekologi bentang lahan tersebut berargumentasi bahwa sistem budidaya wanatani memiliki keanekaragaman hayati yang tergolong tinggi sehingga tidak ada biodiversity gapyang nyata antara kawasan intra taman nasional terhadap kawasan penyangganya. Dalam keadaan tersebut, mamalia kecil maupun mamalia berukuran sedang dapat bebas keluar-masuk diantara kedua kawasan itu, sehingga mamalia besar seperti harimau (sebagai puncak peramida rantai makanan) dan gajah berkecukupan pasokan pangannya, yang secara instinctive mamalia besar tersebut tidak perlu keluar ke kawasan penyangga. Namun tidaklah demikian pada kawasan penyangga yang tidak berpola tanam wanatani, ada tensi biodiversity gap yang nyata terhadap kawasan intrataman nasional sehingga mendorong harimau dan gajah untuk keluar ke kawasan penyangga untuk mencari tanaman budidaya maupun ternak penduduk, yang seringkali harus berhadapan dan berakhir konflik dengan manusia. Situasi seperti itu makin nyata ketika musim kemarau ketika tanaman budidaya di kawasan penyangga masih terawat dan tumbuh baik (yang disukai gajah) yang juga dapat menopang kehidupan mamalia kecil dan sedang yang menjadi incaran harimau. Dengan demikian secara ekologis kawasan, maka keberlanjutan sistem repong damar perlu untuk tetap dipertahankan.

Pasca krisis ekonomi, keberlanjutan sistem repong damar mulai mengkawatirkan akibat harga getah damar yang terus menurun sehingga banyak para petani yang menebangi pohon dammar mereka karena adanya insentif harga kayu yang mahal (Arief 2003). Bahkan seperti dilaporkan oleh surat kabar lokal perilaku tersebut semakin marak sampai dewasa ini (Lampung Pos 2011). Namun studi yang dilakukan oleh Sakinah (2006) memperlihatkan bahwa yang lebih menjadi penyebab utama adalah sistem tataniaga getah damar yang sangat tidak menguntungkan petani. Sebagian besar petani $(63,33 \%)$ terpaksa dihadapkan pada saluran tataniaga terpanjang sebelum sampai ke tangan eksportir. Minimnya akses informasi pasar yang menjadi penyebabnya. Namun penyebab yang lebih mendasar lagi karena umumnya para petani kurang memperhatikan pengelolaan kualitas pascapanen sehingga tidak punya posisi tawar yang kuat. Karena itu Sakinah menyarankan untuk dilakukan pelatihan-pelatihan pascapanen, penguatan kelompok untuk mengembangkan jejaring 
maupun posisi tawar agar ke depan kehidupan para petani repong damar tidak semakin terpuruk, sehingga tidak perlu melikuidasi tegakan pohon-pohon damarnya.

Kekawatiran Sakinah tersebut kini makin nyata. Bila diperiksa data yang tersedia di BPS Kabupaten Lampung Barat (2011), ternyata desa-desa yang berbatasan dengan kawasan TNBBS umumnya merupakan desa-desa miskin. Kelompok masyarakat ini akan mengalami beban yang lebih berat ketika terjadi kenaikan harga-harga misalnya akibat pengurangan subsidi BBM. Belum banyak peneliti yang mempublikasikan hasil karyanya tentang dampak pengalihan subsidi BBM terhadap kesejahteraan masyarakat miskin khususnya yang berada di sekitar kawasan hutan. Diantara yang langka itu adalah yang dilaporkan Cahyono (2010), yang menyimpulkan bahwa ternyata pengalihan subsidi BBM menjadi BLT telah menyebabkan masyarakat penyadap getah pinus menjadi kurang produktif dan meningkatkan belanja yang sifatnya lebih konsumtif. Tetapi bila BLT ditiadakan, maka kemiskinan masyarakat ini makin parah. Di sisi lain BLT juga dapat meningkatkan pengeluaran untuk belanja pendidikan dan kesehatan. Sehubungan dengan itu Cahyono menyarankan agar penyaluran BLT perlu disertai dengan pendidikan kewirausahaan agar masyarakat sekitar hutan dapat memanfaatkan untuk kegiatan yang produktif sekaligus untuk menekan sifat konsumerisme masyarakat yang sudah termarjinalkan pula seperti ini. Oleh karena perlu dirancang suatu kebijakan publik yang mampu memfasilitasi kelompok masyarakat miskin untuk dapat eksit dari perangkat kemiskinan melalui pengalihan subsidi BBM.

Peningkatan ketrampilan melalui pelatihan dalam rangka peningkatan produktivitas budidaya damar, dalam penanganan pascapanen, dalam berjejaring, dalam peningkatan akses pasar merupakan bentuk-bentuk pengasuhan atau pemberdayaan masyarakat di kawasan KDTI ini seperti yang disarankan oleh Sakinah (2006) maupun Cahyono (2010). Bila tidak, maka masyarakat yang secara umum merupakan masyarakat yang paling marjinal ini akan lebih memilih cara yang paling cepat untuk mengatasi beban hidupnya yang makin berat akibat kenaikan harga BBM, yaitu dengan menebangi pohon-pohon damar untuk dijual kayunya. Bila demikian, pohon damar (Shorea javanica)yang menjadi inti tegakan vegetasi dalam sistem hutan ataupun sistem budidaya repong damar tersebut akan menyusut dan mengancam keberadaan best practice dalam pengelolaan sumberdaya hutan berbasis masyarakat setempat tersebut.

Lebih dari itu yang dikawatirkan lagi dari resiko terburuk dari skenario pilihan kebijakan kenaikan BBM itu adalah: kelompok masyarakat ini akan melakukan penetrasi ke dalam kawasan intra TNBBS yang merupakan kawasan konservasi dunia tersebut. Catatan Dinas Kehutanan Provinsi Lampung 2005 (Watala 2008) menunjukkan bahwa kawasan intra TNBBS ini telah mengalami kerusakan sekitar $16 \%$ akibat perambahan. Karena itu dampak terburuk tersebut perlu dicegah, dimulai dengan melakukan karakterisasi perilaku masyarakatnya, kinerja sosial ekonominya, dan kinerja biofisik wilayahnya, dilanjutkaan dengan strategi perancangan pemberdayaan melalui pemodelan seperti direncanakan dalam penelitian ini.

Namun sampai dewasa ini belum ada model prediksi untuk menfasilitasi upaya-upaya eksitdari perangkap kemiskinan yang dikhususkan ke wilayah penyangga kawasan konservasi yang sangat ketat seperti taman nasional apalagi yang dikaitkan dengan dampak kebijakan fiskal seperti pengalihan subsidi BBM. Padahal secara teoritis masyarakat yang menggantungkan kehidupannya di kawasan seperti ini merupakan masyarakat yang termarjinalkan secara struktural.Mereka menggantungkan hidup di wilayah suboptimal: terpencil, medan yang berat, risiko bencana alam, jauh dari akses pasar maupun dari akses berbagai layanan publik seperti pendidikan; kesehatan; administrasi ataupun layanan sosial lainnya. Di sisi lain, subsidi BBM pasti akan dialihkan mengingat cadangannya yang makin cepat menipis. Menurut BP Migas (Tribune Lampung2012) cadangan minyak bumi Indonesia akan habis paling lama 12 tahun mendatang.

Berdasarkan uraian yang dipaparkan di sini maka dipandang mendesak untuk melakukan penelitian ini. Penelitian ini ditujukan untukmengembangkan model penduga terhadap individu rumah tangga miskin (RTM) yang akan mampu eksit dari kemiskinan akibat dari perubahan kebijakan fiskal khususnya peningkatan pendapatan dari pengalihan subsidi BBM.Apabila hasil penelitian ini 
handal, maka dapat diharapkan untuk diterapkan sebagai model pengentasan dari perangkap kemiskinan melalui skenario pengalihan subsidi BBM di kawasan 23 penyangga taman nasional lainnya di Indonesia yang mengalami masalah serupa seperti dicatat oleh Nurhaida et al. (2007) yaitu Taman Nasional [di Provinsi]: Way Kambas [Lampung], Lauser [NAD dan Sumatera Utara], Siberut [Sumatera Barat], Kerinci Seblat [Sumatera Barat, Bengkulu, Jambi], Bukit Berbak [Jambi], Bukit Dua Belas [Jambi], Bukit Tiga Puluh [Riau], Ujung Kulon [Banten], Gede-Pangrango [Jawa Barat], Gunung Halimun [Jawa Barat], Bromo Tengger-Semeru [Jawa Timur], Baluran [Jawa Timur], Alas Purwo [Jawa Timur], Meru Betiri [Jawa Timur], Bali Barat [Bali], Gunung Rinjani [NTB], Kelimutu [NTB], Komodo [NTT], Tanupen Tanah daru [NTT], Laiwangi Wanggameti [NTT], Bogani Nani Wartabone [Sulawesi Utara], Rawa Aopa [Sulawesi Tenggara, dan Lore Lindu [Sulawesi Tengah].

\section{Metode Penelitian}

Penelitian ini dilakukan dalam April sampai Oktober 2013 di tiga desa miskin untuk memperoleh representasi dari lingkungan budaya dominan Etnis Lampung, Jawa, dan campuran. Skrining telah dilakukan untuk memisahkan antara rumah tangga miskin (RTM) yang berhasil eksit versus yang masih terperangkap dari kemiskinan pasca pengalihan subsidi BBM tahun 2005. Untuk itu perlu diterapkan model peluang kualitatif atau peluang biner (Pyndick dan Rubinfeld 1998; dan Juanda 2009).Pada setiap desa dipilih sekitar 50 RTM dari daftar penerima BLT tahun 2005, kemudian dilakukan wawancara mendalam semi terstruktur menggunakan kuesioner untuk menangkap kinerja perekonomian masing-masing RTM. Variabel responnya $\left(Y_{i}\right)$ berupa variabel biner yaitu status kemiskinan rumah tangga ke- $i$, jika berhasil eksit diberi skor 1 jika pendapatan keluarga tidak termasuk miskin dan jika masih terperangkap kemiskinan diberi skor 0 (RTM=rumah tangga miskin jika penghasil<2USD/hari).

Variabel penduga yang digunakan $\left(X_{i j}\right)$ antara lain: harga BBM premium/solar (Rp/liter), jarak tempuh ke pusat desa, kota kecamatan maupun ke Kota Kabupaten (menit), tingkat pendidikan KK, jumlah tanggungan (jiwa), nilai aset produktif (Rp juta/KK), jumlah penghasilan dari getah damar (Rp/bln), jumlah penghasilan dari sumber lainnya (Rp/bln), jumlah tabungan/utang (Rp/KK), total dari BLT yang pernah diterima (Rp), bermukim pada desa yang pernah ada PNPM ataukah tidak (jika pernah diberi skor 1, jika belum 0), dan lingkungan etnis dominan Lampung, Jawa, ataukah etnis campuran (berupa variabel dummy $D_{5}$ ). Secara lebih ringkas pada Tabel 1 disajikan variabel independen, pemberian simbol dalam model dan pemberian skornya untuk operasi model peluang kualitatif dalam penelitian ini. 
Tabel 1.

Variabel penduga (predictor), simbolisasi dan pemberian skornya dalam model

\begin{tabular}{|c|c|c|c|}
\hline $\begin{array}{l}\text { Kelompok } \\
\text { variable } \\
\text { penduga }\end{array}$ & Variabel penduga & $\begin{array}{l}\text { Simbolisasi } \\
\text { dalam model }\end{array}$ & $\begin{array}{l}\text { Pemberian skor nilai dan satuannya } \\
\text { dalam model: }\end{array}$ \\
\hline [1] & [2] & [3] & [4] \\
\hline Struktural & $\begin{array}{ll}\text { 1) } & \text { Harga BBM Permium/Solar } \\
\text { 2) } & \text { Total BLT } \\
\text { 3) } & \text { Skema PNPM } \\
\end{array}$ & $\begin{array}{l}{[\mathrm{BBM}]} \\
{[\mathrm{BLT}]} \\
{[\mathrm{PNPM}]}\end{array}$ & $\begin{array}{l}\text { Rp/liter } \\
\text { Rp Juta/desa } \\
=1 \text { jika ada; =0 jika tidak }\end{array}$ \\
\hline $\begin{array}{l}\text { Kinerja } \\
\text { Demografi }\end{array}$ & $\begin{array}{l}\text { 1) Umur KK } \\
\text { 2) Kelamin KK (Pengambil Keputusan) } \\
\text { 3) Pekerjaan KK } \\
\text { 4) Jumlah Tanggungan } \\
\text { 5) Pendidikan KK }\end{array}$ & $\begin{array}{l}{[\mathrm{UMR}]} \\
{[\mathrm{KLM}]} \\
{[\mathrm{KRJ}]} \\
{[\mathrm{JTG}]} \\
{[\mathrm{D} 1 \mathrm{SD}]} \\
{[\mathrm{D} 2 \mathrm{SLP}]} \\
{[\mathrm{D} 3 \mathrm{SLA}]}\end{array}$ & $\begin{array}{l}\text { Tahun } \\
=1 \text { jika pria; =0 jika wanita } \\
=1 \text { jika petani, =0 jika lainnya } \\
\text { Jumlah jiwa } \\
=1 \text { jika SD; =0 jika lainnya } \\
=1 \text { jika SLP; =0 jika lainnya } \\
=1 \text { jika SLA ke atas; =0 jika lainnya }\end{array}$ \\
\hline $\begin{array}{l}\text { Aksesibilitaske } \\
\text { Layanan Publik }\end{array}$ & $\begin{array}{l}\text { 1) Jarak rumah ke Pusat Desa } \\
\text { 2) Jarak ke rumah ke Kecamatan } \\
\text { 3) Jarak ke rumah ke Kabuapten } \\
\text { 4) Jarak ke kawasan Hutan } \\
\text { 5) Ada/tidaknya Jaringan Listrik ke } \\
\text { rumah }\end{array}$ & $\begin{array}{l}\text { [JRD] } \\
\text { [JRC] } \\
\text { [JRK] } \\
\text { [JRH] } \\
\text { [LST] }\end{array}$ & $\begin{array}{l}\text { Per } 10 \mathrm{Km} \\
\text { Per } 10 \mathrm{Km} \\
\text { Per } 10 \mathrm{Km} \\
\text { Per } 10 \mathrm{Km} \\
=1 \text { jika ada; =0 jika tidak ada }\end{array}$ \\
\hline $\begin{array}{l}\text { Kinerja } \\
\text { ModalSosial }\end{array}$ & $\begin{array}{l}\text { 1) Trust } \\
\text { 2) Norma } \\
\text { 3) Network }\end{array}$ & $\begin{array}{l}{[\mathrm{TRS}]} \\
{[\mathrm{NRM}]} \\
{[\mathrm{NTW}]}\end{array}$ & $\begin{array}{l}=1 \text { jika besar; }=0 \text { jika lemah } \\
=1 \text { jika kuat; = } 0 \text { jika lemah } \\
=1 \text { jika kuat; =0 jika lemah }\end{array}$ \\
\hline Penyuluhan & Ada/tidaknya Penyuluhan 1 thn terakhir & [D4_PNY] & =1 jika ada; =0 jika lainnya \\
\hline $\begin{array}{l}\text { Aset Produktif } \\
\text { RTM }\end{array}$ & $\begin{array}{l}\text { 1) Luas penguasaan lahan kering } \\
\text { 2) Luas penguasaan sawah } \\
\text { 3) Jumlah Nilai ternak } \\
\text { 4) Pendapatan dari repong dammar } \\
\text { 5) Pendapatan lain per bulan }\end{array}$ & $\begin{array}{l}{[\mathrm{LDG}]} \\
{[\mathrm{SWH}]} \\
{[\mathrm{TNK}]} \\
{[\mathrm{ROP}]} \\
{[\mathrm{PDT}]}\end{array}$ & $\begin{array}{l}\mathrm{Ha} \\
\mathrm{Ha} \\
\mathrm{Rp} \\
\mathrm{Rp} \text { Juta/bulan } \\
\mathrm{Rp} \text { Juta/bulan }\end{array}$ \\
\hline Etnis Budaya & $\begin{array}{l}\text { 1) Etnis Lampung } \\
\text { 2) Etnis Jawa } \\
\text { Catatan: Etnis campuran sebagai re }\end{array}$ & $\begin{array}{l}{[\mathrm{LMP}]} \\
{[\mathrm{JAW}]} \\
\text { si bagi } 2 \text { etnis }\end{array}$ & $\begin{array}{l}=1 \text { Jika Lampung=0 jika lainnya } \\
=1 \text { Jika jawa; =0 jika lainnya } \\
\text { nya }\end{array}$ \\
\hline
\end{tabular}

Berdasarkan spesifikasi variabel seperti yang dideskripsikan pada Tabel 1 tersebut maka bentuk model yang diujui dapat diungkapkan dalam Persamaan $\{1\}$ berikut:

$\operatorname{Ln}\left[P\left(\underline{X}_{i}\right)\right] /\left[1-P\left(\underline{X}_{i}\right)\right]=\beta_{1}+\beta_{2}[\mathrm{BBM}]_{\mathrm{i}}+\beta_{3}[\mathrm{BLT}]_{\mathrm{i}}+\beta_{4}[\mathrm{PNPM}]_{\mathrm{i}}+\beta_{5}[\mathrm{UMR}]_{\mathrm{i}}+\beta_{6}[\mathrm{KLM}]_{\mathrm{i}}$ $+\beta_{7}[\mathrm{KRJ}]_{\mathrm{i}}$

$$
\begin{aligned}
& \quad+\beta_{8}[\mathrm{JTG}]_{\mathrm{i}}+\beta_{9}\left[\mathrm{D}_{1 \mathrm{SD}}\right]_{\mathrm{i}}+\beta_{10}\left[\mathrm{D}_{2 \mathrm{SLP}}\right]_{\mathrm{i}}+\beta_{11}\left[\mathrm{D}_{3 \mathrm{SLA}}\right]_{\mathrm{i}}+\beta_{12}[\mathrm{JRD}]_{\mathrm{i}}+\beta_{13}[\mathrm{JRC}]_{\mathrm{i}} \\
& +\beta_{14}[\mathrm{JRK}]_{\mathrm{i}} \\
& +\beta_{15}[\mathrm{JRH}]_{\mathrm{i}}+\beta_{16}[\mathrm{LST}]_{\mathrm{i}}+\beta_{17}[\mathrm{NRM}]_{\mathrm{i}}+\beta_{18}[\mathrm{TRS}]_{\mathrm{i}}+\beta_{19}[\mathrm{NTW}]_{\mathrm{i}}+\beta_{20}\left[\mathrm{D}_{4 \mathrm{PNY}}\right]_{\mathrm{i}} \\
& +\beta_{21}[\mathrm{LDG}]_{\mathrm{i}}+\beta_{22}[\mathrm{SWH}]_{\mathrm{i}}+\beta_{23}[\mathrm{TNK}]_{\mathrm{i}}+\beta_{24}[\mathrm{ROP}]_{\mathrm{i}}+\beta_{25}[\mathrm{PDL}]_{\mathrm{i}}+\beta_{26}\left[\mathrm{D}_{5 \mathrm{LPM}}\right]_{\mathrm{i}} \\
& +\beta_{27}\left[\mathrm{D}_{5 \mathrm{JW}}\right]_{\mathrm{i}}+\varepsilon_{\mathrm{i}}
\end{aligned}
$$

dalam Persamaan $\{1\}$ tersebut:

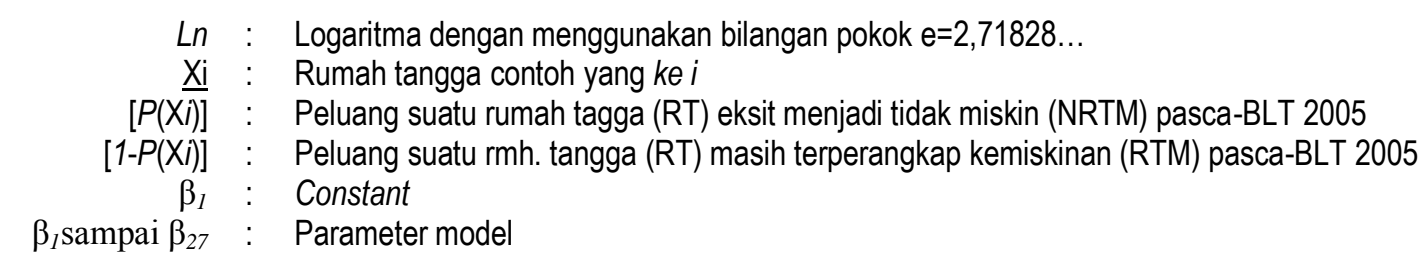




\author{
$\varepsilon_{\mathrm{i}}:$ Error (galat) model \\ Simbol lain : Variabel penduga (penjelas), seperti disimbolkan pada Tabel 1 Kolom [3].
}

Optimasi parameter model menggunakan Minitab Version 16. Uji kebaikan-suai (goodness test of fit) terhadap model menggunakan Uji Gald (taraf 5\% dan 10\%) dan uji terhadap tiap parameter yang digunakan dalam model menggunakan Uji Wald juga pada taraf nyata 5\% dan $10 \%$.

\title{
Hasil dan Pembahasan
}

Hasil analisis parameter regresi peluang kualitatif disajikan pda Tabel 2.Seperti dapat dilihat pada Tabel 2, bahwa nilai parameter Costant $\left[\beta_{1}\right]=0.2350$ dengan $P$-value $=0.569$. Maknanya adalah bahwa apabila variabel lain tidak berubah (tidak diubah misalnya dengan suatu kebijakan), maka peluang suatu RTM (rumah tangga miskin) untuk dapat keluar dari perangkap kemiskinan sangat kecil walaupun nilainya positif. Artinya agar dapat eksit dari perangkap kemiskinan, maka perlu ada perubahan variabel melalui suatu intervensi kebijakan tertentu misalnya dengan pemberian subsidi, peningkatan akses layanan dsb.

\section{Pengaruh kelompok variabel struktural}

Tiga variabel struktural yang dikaji dalam penelitian ini adalah subvariabel harga BBM, jumlah BLT dan ada-tidaknya proyek PNPM di desa dimana RTM berada. Ketiga variabel ini merupakan variabel yang nilainya sangat ditentukan oleh kebijakan fiskal yang merupakan domain dari pemerintah pusat. Dalam konteks ini, untuk variabel harga BBM dapat menurunkan secara nyata peluang suatu RTM untuk dapat eksit dari perangkap kemiskinan dimana setiap ada kenaikan BBM Rp 1.000,-/liter maka kemampuan tersebut turun menjadi hanya 0,37 kali semula (sebelum ada kenaikan harga BBM). Argumentasi ini dapat dibuktikan oleh nilai-nilai prediktor nomor 3 pada Tabel 2. yaitu $\beta_{12}=-1.8510 ; P$-value $=0,000$ dan Odds Ratio= 0,37 .

Variabel ke dua dari variabel struktural yang dikaji adalah besarnya BLT yang diterima tahun 2005. Seperti dapat diperiksa pada Tabel2 bahwa variabel ini mempunyai pengaruh yang nyata $(P$. value $=0,021)$ dalam memberdayakan RTM untuk dapat eksit dari perangkap kemiskinan; setiap ada kenaikan BLT Rp100 ribu maka peluang tersebut akan menjadi 2,11 kali semula (Odds Ratio=2,11). Begitu pula dengan ada-tidaknya PNPM di desa yang bersangkutan; bahwa apabila ada 1 proyek PNPM maka kemampuan rata-rata suatu RTM akan dapat lepas dari perangkap kemiskinan akan meningkat 1,50 kali semula (Odds Ratio=1,50). Kebijakan fiskal berupa pengalihan subsidi baik BLT maupun PNPM dalam penelitian ini memberikan bukti dapat meningkatkan keberdayaan masyarakat di lokasi penelitian ini. Nampaknya multiplier effect dari kedua kebijakan fiskal ini saling sinergis. 
Tabel 2.

Hasil optimasi parameter setiap variabel beserta nilai Odds Ratio-nya dalam modelpeluang kualitatif untuk lepas dari perangkap kemiskinan

\begin{tabular}{|c|c|c|c|c|c|}
\hline No. & Predictor & Simbol & Coef $[\boldsymbol{\beta n}]$ & P_value & $\begin{array}{l}\text { Odds } \\
\text { Ratio }\end{array}$ \\
\hline 1. & Constant & - & {$[\beta 1]=0.2350$} & 0.569 & - \\
\hline \multicolumn{6}{|c|}{ Struktural } \\
\hline 2. & Harga BBM & [BBM] & {$[\beta 2]=(1.8510)^{* *}$} & 0.000 & 0.37 \\
\hline 3. & Jumlah BLT & {$[\mathrm{BLT}]$} & {$[\beta 3]=0.0311 *$} & 0.021 & 2.11 \\
\hline 4. & Adanya Proyek PNPM & [PNPM] & {$[\beta 4]=2.8811 *$} & 0.029 & 1.50 \\
\hline \multicolumn{6}{|c|}{ Demografi } \\
\hline 5. & Umur KK & [UMR] & {$[\beta 5]=(0.1110)$} & 0.511 & 0.72 \\
\hline 6. & Jenis Kelamin KK & [KLM] & {$[\beta 6]=1.3331^{*}$} & 0.041 & 2.44 \\
\hline 7. & Pekerjaan Utama & {$[\mathrm{KRJ}]$} & {$[\beta 7]=(0.88910)$} & 0.312 & 0.89 \\
\hline 8. & Jumlah Tanggungan & [JTG] & {$[\beta 8]=(1.2270)^{*}$} & 0.025 & 0.35 \\
\hline 9. & Dummy KK Lulus SD & [D1SD] & {$[\beta 9]=0.8911$} & 0.671 & 1.01 \\
\hline 10. & Dummy KK lulus SLP & [D2SLP] & {$[\beta 10]=1.4452$} & 0.771 & 1.03 \\
\hline 11. & Dummy KK lulus SLA & [D3SLA] & {$[\beta 11]=1.1117^{*}$} & 0.029 & 2.67 \\
\hline \multicolumn{6}{|c|}{ Aksesibilitas Wilayah ke Layanan } \\
\hline 12. & Jarak RTM ke Pusat Desa & [JRD] & {$[\beta 12]=2.1111$} & 0.671 & 1.03 \\
\hline 13. & Jarak RTM ke Pusat Kec. & {$[\mathrm{JRC}]$} & {$[\beta 13]=(1.3399 *)$} & 0.015 & 0,32 \\
\hline 14. & Jarak RTM ke Pusat Kab. & {$[\mathrm{JRK}]$} & {$[\beta 14]=(0.8997)$} & 0.523 & 0.96 \\
\hline 15. & Jarak RTM ke Batas TNBBS & {$[\mathrm{JRH}]$} & {$[\beta 15]=(0.3312)$} & 0.511 & 0.99 \\
\hline 16. & Jaringan Listrik ke RTM & {$[\mathrm{LST}]$} & {$[\beta 16]=2.1991 * *$} & 0.009 & 3.55 \\
\hline \multicolumn{6}{|c|}{ Modal Sosial \& Penyuluhan } \\
\hline 17. & Kekuatan Norma RTM & [NRM] & {$[\beta 17]=0.4457$} & 0.213 & 1.08 \\
\hline 18. & Kekuatan Trust RTM & {$[\mathrm{TRS}]$} & {$[\beta 18]=0.2213$} & 0.459 & 1.07 \\
\hline 19. & Intesitas Network RTM & [NWK] & {$[\beta 19]=2.5571^{*}$} & 0.029 & 3.89 \\
\hline 20. & Dummy Penyulh. 1 Thn Terakhir & [D4_PNY] & {$[\beta 20]=0.0091$} & 0.289 & 1.06 \\
\hline \multicolumn{6}{|c|}{ Kepemilikan Aset Produktif } \\
\hline 21 & Luas Penguasaan Repong & [LDG] & {$[\beta 21]=3.8891^{*}$} & 0.037 & 8.91 \\
\hline 22. & Luas Penguasaan Sawah & {$[\mathrm{SWH}]$} & {$[\beta 22]=2.112 *$} & 0.021 & 6.33 \\
\hline 23. & Jumlah Nilai Ternak & [TNK] & {$[\beta 23]=0.2901$} & 0.028 & 2.83 \\
\hline 24. & Penghasilan dari Repong & [ROP] & {$[\beta 24]=1.5567^{*}$} & 0.017 & 7.88 \\
\hline 25. & Pendapatan Lain & [PDL] & {$[\beta 25]=0.5211$} & 0.291 & 1.33 \\
\hline \multicolumn{6}{|c|}{ Lingkungan Etnis-Budaya } \\
\hline 26. & Dummy Etnis KK Lampung & [D5_LMP] & {$[\beta 26]=1.2510$} & 0.167 & 1.01 \\
\hline 27. & Dummy Etnis KK Jawa & [D5_JAW] & {$[\beta 27]=1.349$} & 0.219 & 1,06 \\
\hline \multicolumn{6}{|c|}{ Catatan: Etnis campuran sebagai referensi bagi 2 etnis lainnya } \\
\hline
\end{tabular}

Sumber: Data primer; Keterangan angka dalam tanda() bernilai negatif; tanda *berarti nyata pada taraf $10 \%$ dan ** berarti nyata pada taraf $5 \%$.

\section{Pengaruh kelompok variabel demografi}

Variabel umur KK berpengaruh negatif terhadap keberdayaan RTM dalam penelitian ini menunjukkan bahwa keberdayaan RTM untuk dapat lepas dari perangkap kemiskinan menjadi hanya 0,72 dari semula (Odds Ratio $=0,72$ ) jika umur KK bertambah atau lebih tua satu tahun. Namun pengaruh penurunan ini tidak nyata $\left(P_{\text {-value }}=0,511\right)$. Sebaliknya untuk variabel jenis kelamin KK berpengaruh nyata; pada KK pria 2,44 kali KK wanita dalam hal keberdayaannya untuk dapat lepas dari perangkap kemiskinan seperti ditunjukkan oleh nilai Odds Ratio-nya yang sebesar 2,44.

Temuan ini menunjukkan bahwa keputusan-keputusan tatalaksana budidaya repong damarlebih bersifat maskulin. Dalam konteks ini nampaknya pria masih lebih leluasa dalam mengambil berbagai keputusan yang berkenaan dengan berbagai urusan dalam budidaya repong damar, termasuk dalam hal mobilitasnya untuk pergi ke berbagai tempat untuk mencari informasi tanpa banyak dibatasi oleh waktu siang ataupun malam hari. 
Di sisi lain jumlah tanggungan keluarga nampaknya cenderung lebih merupakan beban dari pada menjadi potensi dalam membantu untuk dapat keluar dari perangkap kemiskinan sebagaimana dicermin oleh nilai $\beta 7=-1,2270$ ).Dalam hal ini, bahwa jika dalam RTM ada tambahan satu orang tanggungan maka kemampuan RTM itu untuk dapat lepas dari perangkap kemiskinan akan menjadi hanya 0,89 kali semula (Odds Ratio-nya $=0,89$ ); penurunan kemampuan ini bersifat nyata $(P$ value $=0,025)$.

Pengaruh jenjang pendidikan KK mulai darilevelSD sampai SLP tidak berbeda nyata dalam kemampuannya untuk dapat lepas dari perangkap kemiskinan. Hanya jika level pendidikan KK yang SLAsaja yang mempunyai perbedaan nyata dibandingkandengan jenjang pendidikan SLTP ke bawah.Pada KK yang memiliki jenjang pendidikan SLAmaka kemampuan untuk lepas dari perangkap kemiskinan adalah 2,67 kali yang KK dengan level pendidikan SLP ke bawah (Odd Ratio $=2,67)$. Perbedaan ini berpengaruh nyata $(P$-value $=0,029)$. Temuan ini menyumbangkan bukti bahwa bila tanpa disertai dengan kebijakan pengirim lainnya,maka hanya KK yang mempunyai pendidikan selevel SLA ke atas saja yang dapat diharapkan untuk dapat eksit dari perangkap kemiskinan rumah tangganya. Mereka yang lulus SLP ke bawah nampaknyabelum cukup handaldalam upaya keberdayaan untuk lepas dari perangkap kemiskinan tanpa disertai dengan kebijakan lainseperti pemberian subsidi, peningkatan aset produktif, peningkatan layanan publik dsb.

\section{Pengaruh variabel aksesibilitas wilayah kelayanan publik}

Jarak layanan yang dikaji dalam penelitian ini adalah jarak tiapRTM terhadap pusat desa, terhadap pusat kecamatan, dan terhadap pusat kabupaten. Ketiga variabel ini dapat menjadi penentu terhadap kemudahan mencari layanan sehari-hari maupun dalam mencari informasi misalnya tentang harga sarana produksi, harga output dan sebagainya. Begitu juga dengan ada-tidaknya jaringan listrik yang juga menentukan kemudahan dalam memperoleh informasi di wilayah perdesaan maupun dalam melakukan prosesing hasil getah damar, dan hasil-hasil bumi dari budidaya dalam sistem repong damar. Kecuali itu jarak terhadap TNBBS juga dipandang dapat menentukan bagi RTM untuk dapat memperoleh penghidupan.

Seperti dapat diperiksa pada Tabel 2, bahwa jarak RTM ke pusat desa, tidak berpengaruh nyata terhadap kemampuan RTM untuk dapat lepas dari perangkap kemiskinan. Nampaknya berbagai bentuk informasi cukup tersebar merata diantara sesama warga di dalam desa. Namun jarak RTM ke pusat kecamatan berpengaruh nyata $\left(P_{-v a l u e}=0,01\right)$ terhadap kemampuan RTM untuk dapat lepas dari perangkap kemiskinan; dimana setiap jarak bertambah $10 \mathrm{~km}$ maka kemampuan untuk keluar dari perangkap kemiskinan akan berkurang menjadi 0,32 kali semula (Odds Ratio-nya=0,32); atau dengan kata lain yang punya makna sama bahwa setiap berkurang jarak RTM terhadap pusat kecamatan sebesar $10 \mathrm{~km}$ maka kemampuan tersebut akan menjadi 1/0,32 atau=3,215 kali semula.

Berbeda dengan ketiga macam akses yang telah dibahas tersebut di atas, jarak RTM terhadap TNBBS sekalipun berpengaruh positif terhadap kemampuan RTM untuk dapat eksit dari perangkap kemiskinan makin besar (yaitu jika jarak bertambah $10 \mathrm{~km}$ maka kemampuan tersebut akan bertambah menjadi 1,09 kali semula seperti ditunjukkan oleh Odds Ratio-nya yang sebesar 1,09). Namun pengaruh tersebut tidak nyata. Artinya masyarakat di kawasan penyangga ini tidak begitu menggantungkan mata pencaharaiannya secara langsung ke sumber-sumberdaya alam yang dalam kawasan hutan konservasi yang dilindungi peraturan-perundangan secara ketat ini.Dengan kata lain bahwa dengan semakin kuatnya repong damarsebagai sumber matapencaharian,maka doronganmasyarakat untuk merambah TNBBS juga semakin kecil. Sehubungan dengan ini maka, memperkuat pendapatan masyarakat dari hasilbudidaya repong damar harus terus dilakukan agar tekanan terhadap TNBBS menjadi berkurang yang berarti kelestarian TNBB dapat lebih diharapkan.

Selain itu, adanya jaringan listrik ke RTM juga berpengaruh sangat nyata bagi kemampuan RTM untuk dapat eksit dari perangkap kemiskinan. Sebagaimana dapat diperiksa pada Tabel 2, bahwa 
RTM yang mendapatkan aliran listrik maka kemampuannya untuk dapat lepas dari perangkap kemiskinan adalah 3,55 dibandingkan dengan yang belum mendapat fasilitas layanan listrik (Odds Ratio=3,55).Perbedaan ini sangat nyata seperti diekspresikan oleh nilai $P_{\text {-value }}$ yang $=0,009$. Fenomena ini memberi bukti bahwa layanan listrik telah menjadi faktor produksi yang sangat penting di perdesaan tidak terkecuali perdesaan yang menjadi sentra produksi getah damar ini.

Berkaitan dengan adanya jaringan listrik, aktivitas perekonomianseperti prosesing getah damar akan menjadi lebih baik.Demikian pula waktu bekerja untuk keperluan sehari-hari dalam rumah tangga, sehingga waktu untukleisure juga lebih baik termasuk untuk hiburan yang bersumber dari radio, TV ataupun berbagai sumber informasi yang berasal dari media elektronik ini termasuk untuk informasi harga sarana produksi maupun harga getah damar dapat diperoleh lebih cepat. Perekonomian menjadi lebih giat dan pada akhirnya berdampak positif terhadap kemampuan RTM untuk dapat eksit dari perangkap kemiskinan. Implikasi pada kebijakan yang lebih luas bahwa penguatan PNPM di sektor energi perdesaan seperti mikrohidro menjadi pilihan yang tepat untuk meningkatkan suplai daya listrik utamanya untuk memperluas ke RTM-RTM yang belum memperoleh aliran listrik murah ataupun sekaligus untuk memenuhi peningkatkan kebutuhan akan energi listrik seiring dengan semakin meningkatkan kesejahteraan perekonomian perdesaan itu.

\section{Pengaruh kelompok variabel modal sosial dan kinerja penyuluhan}

Modal sosial yang dimiliki oleh setiap RTM dipandang juga punya peranan penting dalam konteks keberdayaan RTM untuk lepas dari perangkap kemiskinan. Unsur norma (norm) merupakan unsur modal sosial pertama. Dengan adanya norma yang kuat dalam suatu masyarakat, maka seorang individu dapat diharapkan untuk memulaiberani menanamkan trust kepada individu lain yang selanjutnya dapat digunakan sebagai dasar untuk melakukan relasi atau berhubungan dan berinteraksi maupun saling bertransaksi dengan individu lainbaik dengan sesama warga di desanya maupun dengan orang lain dari luar desa. Dengan menguatnya trust, maka pada akhirnya dapat terbentuk dan terbangun jejaring (network) yang kuat dan intensif.Oleh karena itu modal sosial (yang merupakan modal yang tidak kasat mata atau intangibel) ini sangat penting dalam kehidupan (perekonomian) di belahan dunia manapun, tidak terkecuali di perdesaan.

Dalam penelitian ini ketiga unsur modal sosial (norm, trust \& network) tersebut berpengaruh positif terhadap kemampuan RTM untuk dapat eksit dari perangkap kemiskinan sebagaimana diekspresikan oleh ketiga nilai Odds Ratio-nya yang lebih besar dari 1.Namun demikian, dalam penelitian ini ternyata hanya pengaruh jejaring (network) dari RTM yang bersifat nyata $(P$. value $=0,29)$, sedangkan kedua unsur modal sosial lainnya tidak. Fenomena ini menunjukkan bahwa tingkat kekuatan norm \& trust sesama warga sudah relatif tinggi. Namun sebaliknya nampaknya unsur network relatif belum setinggi norm ataupun trust.Dengan kata lain network masyarakat di kawasan ini masih relatif lemah. Nampaknya network yang lemah ini yang dapat menjelaskan mengapa terjadinya market buyers dalam pemasaran getah damar yang umumnya harus melalui rantai pemarasan yang relatif panjang (termasuk harus melalui tengkulak) sebelum mencapai eksportir sehingga perangkap kemiskinan masih masif (lihat Sakinah2006).

Oleh karena itu dengan pengembangan network masih punya peranan nyata bagi akselarasi eleviasi kemiskinan di wilayah penelitian ini. Seperti yang dilakukan oleh Vipriyanti (2007) dalam penelitan ini network diproksi dengan banyaknya kawan dekat, dimana jika kawan dekat bertambah 1 orang, maka kemampuan RTM untuk dapat eksit dari perangkap kemiskinan akan meningkat menjadi 3,89 kali semula sebagaimana diekspresikan dengan Odds Ratio=3,89.

Berlandaskan pada temuan ini, maka ke depan investasi dalam penguatan network bagi RTM di wilayah penelitian juga merupakan suatu kebijakan yang strategis seperti penguatan kelompok, gapoktan, pertemuan keagamaan, pertemuan arisan ataupun penyuluhan dll. Sejalan dengan ini dalam penelitian ini ditemukan bahwa pengaruh ada-tidaknya penyuluhan 1 tahun terakhir berpengaruh nyata terhadap kemampuan RT untuk lepas dari perangkap kemiskinan ( $P$ - 
value $=0,026$ ), dimana kemampuan tersebut menjadi 2,56 kali dibandingkan bagi RTM yang tidak memperoleh penyuluhan.

\section{Pengaruh kepemilikan aset produktif}

Baik luasan penguasaan lahan repong damarmempengaruhi secara nyata terhadap kemampuan RTM untuk dapat lepas dari perangkap kemiskinan. Jika luasan repong bertambah 1 ha, maka kemampuan lepas tersebut berlipat ganda menjadi 8,91 kali semula (Odds Ratio=8,91). Pengaruh ini sangat nyata seperti diekspresikan oleh $P$-value $=0,009$. Demikian juga halnya dengan kepemilikan sawah, dimana kemampuan untuk dapatlepas dari perangkap kemiskinan tersebut akan menjadi 6,33 kali semula setiap penambahan kepemilikan 1ha sawah.Namun demikian menambah luasan repong maupun sawah bukan berarti solusi yang tepat untuk upaya-upaya eleviasi dari kemiskinan, karena akan menyebabkan pada implikasi terjadinya polarisasi kapital pada sekelompok kecil yang justru dapat menyulitkan reformasi agraria. Temuan ini perlu untuk lebih dimaknai pada upaya sebaliknya, yaitu agar tidak terjadi penurunan (devolusi) kepemilikan lahan repong bagi RTM agar tidak terjadi fragmentasi lahan yang dapat melebarkan disparitas kesejahteraan masyarakat di wilayah penelitian ini.

Aset produktif lainnya yang dapat dijadikan fasilitasi untuk kebijakan percepatan elevisi dari perangkap kemiskinan bagi RTM di wilayah penelitian ini adalah kepemilikan ternak (diproksi dengan nilai ternak ruminansia). Jika nilai ternak ruminan yang dimiliki oleh suatu rumah tangga bertambah sebesar setara Rpljuta, maka kemampuan untuk dapat lepas dari perangkap berlipat ganda menjadi 2,83 kali semula. Peran kepemilikan ternak ini nyata dalam upaya untuk eleviasi dari perangkap kemiskinan sebagaimana ditunjukkan oleh nilai $P$-value-nya yang $=0,028$. Temuan ini dapat digunakan sebagai justifikasi ilmiah betapa kebijakan penguatan atau diversifikasi pendapatan melalui pemilikan ternak merupakan prospek yang sangat baik, apalagi jika dikaitkan dengan kebutuhan akan swasembada daging, pemenuhan gizi keluarga dsb. Tampaknya temuan ini juga sejalan dengan yang dilaporkan oleh Saputri et al. (2014)bahwa sistem budidaya repong damar cukup dapat diharapkan untuk mampu menopang pembangunan sumberdaya manusia melalui pemenuhan gizi dan kesehatan balita.

Dalam kaitannya dengan pendapatan dari sistem budidaya repong damar ini dapat menjadikan akumulasi modal bagi RTM untuk mengakselesari bagi proses eksit dari perangkap kemiskinan. Jika pendapatan dari repong damar meningkat Rp 1 juta maka kemampuan tersebut akan meningkat menjadi 7,88 kali semula (seperti ditunjukkan oleh nilai Odds Ratio-nya dan Pvalue-nya dalam Tabel 2). Ini memberikan indikasi bahwa, repong damar masih merupakan tumpuan yang kuat sebagai hajat hidup bagi masyarakat di kawasan penyangga TNBBS ini, tidak terkecuali bagipara RTM yang ada di wilayah penelitian ini.

Namun demikian pendapatan dari luar kegiatan budidaya repong damar walaupun punya pengaruh positif, tetapi pengaruh tersebut tidak nyata. Artinya pekerjaan di luar budidaya repong, budidaya padi sawah maupun budidaya ternakbelum dapat dijadikan andalan bagi upaya untuk eleviasi dari perangkap kemiskinan. Pernyataan ini dapat ditunjukkan oleh rendahnya peran pendapatan lain selain dari ketiga jenis budidaya tersebut dalam meningkatkan peluang eksit dari perangkap kemiskinan. Dalam hal jika pendapatan di luar ketiga pekerjaan tersebut rata-rata bertambah Rp 1 juta, maka pulang untuk dapat eksit dari perangkap kemiskinan hanya akan meningkat menjadi 1,33 kali semula (Odds Ratio=1,33). Peningkatan peluang ini tidak nyata seperti ditunjukkan oleh nilai $P$-value-nya yang sebesar 0,291.Asalkan pohon-pohon damar tidak ditebang untuk diekstrak kayunya, fakta ini juga menjastifikasikan bahwa sistem budidaya repong damar masih dapat menjadi tumpuan bagi keberlanjutanbest practice dalam pengelolaan hutan adat seperti yang telah ditetapkan denganSK Menteri Kehutanan No.47/Kpts-II/1998 ini (Saputri et al. 2014). 


\section{Pengaruh variabel lingkungan etnis-budaya}

Cukup banyak literatur yang mengkaji peranan kemiskinan yang diturunkan dari pewarisan budaya atau kultural sifatnya. Sekalipun budidaya repong damar merupakan kultur teknis dari masyarakat asli di Pesisir LampungBarat, namun di wilayah penelitian ini juga banyak dijumpai Etnis Jawa dan Semendo yang menggantungkan hidupnya dari budidaya repong damar. Dalam penelitian ini pengaruh lingkungan kelompok etnis dapat dibedakan ke dalam 3 katagori yaitu, Lampung, Jawa dan campuran untuk masing-masing yang banyak berdomisili di Desa Pahmungan, Desa Kampung Jawa dan Desa Rawas. Karena Etnis Semendo relatif sedikit populasinya dibandingkan dengan kedua etnis yang lainnya dan umumnya berdomisili di Desa Rawas, maka Etnis Semendo tidak diperlakukan sebagai etnis tersendiri, melainkan sebagaietnis campuran bersama-sama dengan Etnis Lampung dan Jawa tersebut. Etnis campuran yang melebur (melting pot) di Desa Rawasa dalam penelitian ini digunakan sebagai referensi dasar dalam memperbandingkan peluang eksit dari perangkap kemiskinan.

Sebagaimana dapat diperiksa pada Tabel 2,ternyata RTM yang berasal dari masyarakat Etnis Etnis Lampung dalam kemampuannya untuk lepas dari jerat kemiskinan hanyasebesar 1,01 kali Etnis Campuran (Odds Ratio $=1,01)$ dengan $P$-value $=0,167$. Angka ini tidak berbeda nyata. Demikian pula halnya dengan Etnis Jawa, yang mempunyai kemampuan eksit hanya 1,06 kali kemampuan Etnis Lampung (Odds Ratio $=1,06)$, tidak berbeda dengan $P$-value $=2,19$. Temuan ini menunjukkan bahwa kemiskinan di wilayah penelitian ini lebih bersifat struktural dari pada kultural.

\section{Simpulan}

Kemampuan eksit terhadap kemiskinan bagi RTM repong damar damar dipengaruhi secara nyata oleh: hara BBM, besarnya BLT, adanya PNPM, jenis kelamin KK, jumlah tanggungan, tingkat pendidikan KK, jarak RTM ke pusat kecamatan, adanya layanan listrik, kekuatan modal sosial, penyuluhan, luasan kepemilikan lahan repong dan sawah serta aset produktif berupa ternak ruminan. Berdasarkan hasil penelitian, dapat kami simpulkan bahwaetnis budaya tidak berpengaruh nyata, yang mempunyai makna bahwa kemiskinan di wilayah ini lebih berkaitan denganstruktural ketimbang kultural.

\section{Daftar Pustaka}

Arief A (2003) Konversi Kebun Damar Mata Kucing (Shorea javanica): Studi kasus pengambilan keputusan oleh petani di Desa Lubuk Baru, Kecamatan Bay Rayap, Baturaja Kabupaten Ogan Komering Ulu, Sumatera Sealatan. Skripsi IPB Bogor (Tidak Dipublikasi).

BP Migas (2012) Cadangan minyak bumi Indonesia akan habis dalam duabelas tahun. Tribune Lampung, 6 April 2012.

Barrett CB \&Swallow BM (2005) Fractal Poverty Traps. Nairobi:Working Paper,World Agroforestry Centre.

Barrett CB (2011)Assisting the escape from persistent ultra-poverty in rural Africa. Proceeding of the Stanford Symposium Series on Global Food Policy and Food Security in the 21st Century.

Cahyono SA (2010) Dampak bantuan langsung tunai dan investasi sumberdaya manusia terhadap ekonomi rumah tangga sekitar hutan pinus di Desa Samagede. Jurnal Penelitian Sosial dan Ekonomi Kehutanan: 7(2):101-115.

Foresta, H de, Kusworo, A, Michon, G, Djatmiko, WA (2000) Ketika kebun berupa hutan: Agroforest khas Indonesia-Sebuah sumbangan masyarakat. International Centre for Research in Agroforestry, Bogor: Indonesia.

Juanda B (2009) Ekonometrika: Pemodelan dan Pendugaan. Bogor: IPB Pres.

Lampung Post, 15 April 2011. Pohon damar terancam punah. 
Nyhus P \& Tilson R (2004) Agroforestry, elephants and tigers: Balanching conservation theory and practice in human-dominated landscape of Shouth Part of Sumatera, Indonesia. Agriculture, Ecosystem and Environment 104:87-89.

Nurhaida I, Setiawan A, Wiranata GAB \& Syah P (2007) Menanamkan ideologi lingkungan pada masyarakat di kawasan penyangga Taman Nasional Way Kambas menggunakan media hiburan buku cergam dalam rangka pelestarian kampanye keanekaragaman hayati. Laporan Penelitian Hibah Bersaing Perguruan Tinggi XV/1. (Tidak dipublikasi).

Pindyct RS \& Rubinfeld DL (1998) Model of qualitative choice. Econometric Model and Economic Forcast. $4^{\text {th }}$ Ed. Boston: Irwin McGraw-Hill.

Sakinah N (2006) Analisis sistem dan efisiensi tataniaga komoditas damar mata kucing (Shorea javanica) untuk meningkatkan farmer share petani. Skripsi IPB, Bogor. [diakses 10 Maret 2012]www.ipb.ac.id.

Saputri DE, Bakri S, Zuraida R(2014) Peranan sistem repong damar terhadap pendapatan, asupan makan,kesehatan dan status gizi balita: Studi kasus di Desa Pahmungan Kecamatan Pesisir Tengah Kabupaten Pesisir Barat. Skripsi. Jurusan kehutanan Fakultas Pertanian Universitas Lampung. www.unila.ac.id.

Watala (2008) Studi kolaborasi mendukung hutan kemasyarakatan secara lebih adil dan demokratis di Lampung. Laporan Pemberdyaan Masyarakat. Watala. Bandar Lampung.

Vipriyanti NU (2007) Studi sosial ekonomi tentang keterkaitan antara modal sosial dan pembangunan ekonomi wilayah: Studi kasus pada empat kabupaten di Provinsi Bali. Disertasi, SPs IPB Bogor.www.ipb.a.c.id. 